\title{
THE LATE EFFECTS OF BILATERAL CAROTID SINUS DENERVATION IN MAN
}

\author{
Report of Two Cases with Studies of the Vascular Reflexes
}

By RICHARD B. CAPPS ANd GÉZA DE TAKÁTS

(From The Circulatory Group, St. Luke's Hospital, Chicago)

(Received for publication January 17, 1938)

Owing principally to the investigations of Hering (1) and Heymans et al. (2), it is now well established that the carotid sinus and the aortic depressor nerve and its end organs are the chief nervous mechanisms for the regulation of the blood pressure. Considering their importance from a physiological viewpoint, it should not be surprising if surgical interference produced untoward effects. In animals, denervation of both carotid sinuses and section of both depressor nerves has been found by most investigators (1, $3,4,5$ ) to cause a chronic hypertension and tachycardia, an increased lability of the blood pressure and pulse, and often various other disorders. Denervation of the carotid sinuses alone usually results in similar but only temporary changes $(1,4)$. For example, in 8 out of 10 dogs on whom Leriche et al. (6) had performed this operation, the blood pressure and pulse returned to normal in less than two months. However, in the 2 remaining animals there was still an elevation of the blood pressure of 20 and $40 \mathrm{~mm}$. $\mathrm{Hg}$ respectively at the end of this time. Regarding other effects of this operation, especially the effect on postural vascular reflexes, there are very few data in the literature. Hering (1) states that, in dogs, there occurs a greater fall in blood pressure on assuming the standing position than in normal animals. Green and his coworkers (7) noted fainting attacks in 2 of their dogs who had bilaterally denervated carotid sinuses. These attacks may have been on a postural basis.

In man, unilateral denervation of the carotid sinus results in only temporary elevation of the blood pressure and pulse, and, as far as is known, no change in the postural vascular reflexes $(6,8)$. Bilateral carotid sinus denervation in man has not previously been reported in this country. In the European literature there are several reports, but the published data are very meager. Lauwers (9) found no serious effects in 9 cases. He in- cludes no actual figures for blood pressures or pulse rates.

Danielopolu (10) merely reports that the operation has been done and that no hypertension resulted. Five cases were operated upon by Leriche et al. (6) who state that no marked permanent variations in blood pressure or pulse rate occurred. However, figures are given for only 3 of the cases. In one of these the pressure returned to the preoperative level the day of operation; in another there was a hypertension 3 days postoperatively (further observations were not recorded); and in the third case the blood pressure was still elevated at the end of 4 months from a preoperative level of $140 / 70$ to $165 / 85$. In none of the above cases were observations on the effect of posture on the blood pressure recorded.

From this review of the literature, it is apparent that our knowledge of the late effects of bilateral carotid sinus denervation in man is scanty and incomplete. Only resting blood pressures and pulse values have been determined, and then only in a few cases. We were fortunate in having available 2 patients on whom one of us (Géza de Takáts) had performed bilateral carotid sinus denervation $81 / 2$ and 17 months previously. Since both patients were operated upon for epilepsy, complete preoperative data are not available. In spite of this deficiency, a study of the vascular reflexes of these 2 patients at this relatively late date postoperatively has yielded results of sufficient interest to warrant the present report.

\section{METHODS OF STUDY}

The observations made were directed at determining (1) the presence or absence of expected abnormalities in vascular reflexes; (2) the response of the carotid sinuses to stimulation; and (3) the status of another vasovagal reflex, the oculocardiac. Identical tests were made on both patients, and in most cases each test was repeated at least once, and in cases of doubt several times. Where 
marked variations occurred on repetition, the most extreme results have both been recorded. Blood pressures were determined by the auscultatory method. Pulse rates were taken at the wrist, being calculated from consecutive 15-second intervals for the postural and exercise tests. For the other tests an electrocardiograph was used.

In the first category were included observations on the resting blood pressure and pulse, and the changes that occurred on voluntary standing and after exercise. Resting observations were obtained after 15 minutes or more in the supine position. Postural changes were determined by having the patient stand up quickly with as little effort as possible. The blood pressure was taken each 15 seconds and the radial pulse rate counted continuously, while the pulse was calculated for each 15second interval. The findings at the end of 2 minutes are recorded in the tables, since a reasonably constant level seemed to be reached by this time. The effect of exercise was determined by allowing the patients to run up and down one flight of stairs. The maximum change in blood pressure and pulse rate, taken at 15-second intervals as before, is recorded in Table $I$.

In the second category were included observations on the effect of direct carotid sinus pressure and of occlusion of the common carotid low in the neck with sudden release of pressure. The patients were tested in the supine position. The technique has been described in a previous paper (8). Continuous electrocardiographic tracings were made and the pulse calculated therefrom.

TABLE I

Effect of bilateral denervation of the carotid sinus on blood pressure and pulse

\begin{tabular}{|c|c|c|c|c|c|c|c|}
\hline \multirow{2}{*}{ Patient } & \multirow{2}{*}{ Age } & \multirow{2}{*}{ Sex } & \multicolumn{2}{|c|}{$\begin{array}{c}\text { Preoperative } \\
\text { lying }\end{array}$} & \multirow{2}{*}{$\begin{array}{c}\text { Months } \\
\text { post- } \\
\text { operative }\end{array}$} & \multicolumn{2}{|c|}{$\begin{array}{l}\text { Postoperative } \\
\text { lying }\end{array}$} \\
\hline & & & $\underset{\text { pressure }}{\text { Blood }}$ & $\begin{array}{l}\text { Pulse } \\
\text { rate }\end{array}$ & & $\begin{array}{c}\text { Blood } \\
\text { pressure }\end{array}$ & $\begin{array}{l}\text { Pulse } \\
\text { rate }\end{array}$ \\
\hline & years & & mm. $\mathrm{Hg}_{\mathrm{g}}$ & $\begin{array}{c}\text { per } \\
\text { minute }\end{array}$ & & $\mathrm{mm} . \mathrm{Hg}$ & $\begin{array}{c}\text { per } \\
\text { minute }\end{array}$ \\
\hline $\begin{array}{l}\mathbf{M} \ldots \ldots \\
\mathbf{S} \ldots \ldots\end{array}$ & $\begin{array}{l}30 \\
23\end{array}$ & $\begin{array}{l}\mathbf{M} \\
\mathbf{M}\end{array}$ & $\begin{array}{l}102 / 72 \\
120 / 60\end{array}$ & $\begin{array}{l}70 \\
70\end{array}$ & $\begin{array}{l}17 \\
8 \frac{1}{2}\end{array}$ & $\begin{array}{l}102 / 68 \\
122 / 70\end{array}$ & $\begin{array}{l}58 \\
72\end{array}$ \\
\hline
\end{tabular}

Determinations of blood pressure were made as frequently as feasible during the experiment. The maximum changes in pulse (time between two beats) and in blood pressure have been recorded. Changes in respiration and subjective symptoms were also noted. The effects of strong eyeball pressure for a 15-second interval were studied in a similar manner.

\section{MATERIAL}

The 2 patients studied were both cases of severe idiopathic epilepsy. The physical examination and the laboratory findings were essentially negative. The operations were performed by one of us (Géza de Takáts), and consisted of a 2-stage denervation of the carotid sinuses and a 2-stage cervicodorsal sympathectomy. The carotid sinuses were cleanly stripped, as well as the artery, for a distance of $2 \mathrm{~cm}$, both above and below the sinus. (A more complete description of the operation, as well as the effect on the epilepsy, will be discussed in a later publication.) The carotid body was identified at biopsy in one instance. Many autonomic nerve fibers were found in all four biopsy specimens.

As controls for the postural tests, the results obtained by Roth (11) in 37 normal males and in 5 cases of bilateral cervicodorsal sympathectomy were used. Her determinations were made with the same technique as was used here. For the exercise test, 7 normal subjects-5 females and 2 males recruited from the doctors and nurses of the hospital staff-were employed as controls.

\section{RESULTS}

In Table $I$ is recorded the resting blood pressure and pulse of both patients before the operation and at the time of study, along with other pertinent data. It will be noted that there was practically no change in the blood pressure. The significance of the slower pulse in Patient $M$ postoperatively is problematical.

TABLE II

Effect of bilateral denervation of the carotid sinus on postural vascular reflexes and reaction to exercise

\begin{tabular}{|c|c|c|c|c|c|c|c|}
\hline \multirow{2}{*}{ Patient } & \multicolumn{2}{|c|}{ Lying } & \multicolumn{2}{|c|}{ Standing } & \multicolumn{2}{|c|}{$\begin{array}{l}\text { Standing after } \\
\text { exercise }\end{array}$} & \multirow{2}{*}{$\begin{array}{c}\text { Symptoms on } \\
\text { standing }\end{array}$} \\
\hline & $\mid \begin{array}{c}\text { Blood } \\
\text { pres } \\
\text { sure }\end{array}$ & $\begin{array}{l}\text { Pulse } \\
\text { rate }\end{array}$ & $\begin{array}{c}\text { Blood } \\
\text { pressure }\end{array}$ & $\begin{array}{l}\text { Pulse } \\
\text { rate }\end{array}$ & $\begin{array}{c}\text { Blood } \\
\text { pressure }\end{array}$ & $\begin{array}{l}\text { Pulse } \\
\text { rate }\end{array}$ & \\
\hline $\mathbf{M}$ & $\left|\begin{array}{l}m m . H g \\
102 / 68\end{array}\right|$ & $\begin{array}{l}\text { per } \\
\text { ute } \\
58\end{array}$ & $\begin{array}{c}m m . H Q \\
85 / 64\end{array}$ & $\begin{array}{c}\text { per } \\
\text { minute } \\
80\end{array}$ & $\begin{array}{c}m m . H g \\
95 / 65\end{array}$ & $\begin{array}{c}\text { per } \\
\text { min- } \\
\text { ute } \\
100\end{array}$ & None \\
\hline $\mathbf{s}$ & $122 / 70$ & 72 & $\begin{array}{c}106 / 78 \\
\text { or } \\
75 / 60\end{array}$ & 91 & $108 / 70$ & 114 & $\begin{array}{l}\text { Temporary } \\
\text { falntnegs. } \\
\text { Fainted once }\end{array}$ \\
\hline \multicolumn{3}{|c|}{ Controls } & \multicolumn{5}{|c|}{ Average change } \\
\hline \multicolumn{3}{|c|}{$\begin{array}{l}37 \text { Normal males (Roth } \\
\text { (11)) }\end{array}$} & $\begin{array}{r}\text { Sys. }-1.9 \\
\text { Dias. }+9.5\end{array}$ & +15.8 & & & . \\
\hline \multicolumn{3}{|c|}{$\begin{array}{l}5 \text { Cases of bilateral } \\
\text { oervioodorsal sym- } \\
\text { patheotomy (Roth } \\
\text { (11)) }\end{array}$} & $\begin{array}{r}\text { Sys. }+0.8 \\
\text { Dias. }+10.8\end{array}$ & +11 & & & \\
\hline \multicolumn{3}{|c|}{7 Normal subjects } & & & $\begin{array}{l}\text { 8ys. }+20 \\
\text { Dias. }-17\end{array}$ & +31 & None \\
\hline
\end{tabular}

* In the seven normal subjects the average changes in blood pressure and pulse rate are computed from a control level while standing at rest.

Table II shows the effect of posture and of exercise. In both patients it will be noted that there is a marked fall in the systolic blood pressure on assuming the standing position. In both the normal control group and in those with a bilateral 
cervicothoracic sympathectomy, there was no significant change in the systolic pressure. The diastolic pressures in the 2 patients failed to rise in the same manner as in the controls. The fall in blood pressure of Patient $S$ was found to vary considerably. The extremes of this variation have both been included in Table II. In the second instance a pressure of 58/45 was maintained for a full minute before it gradually rose to $75 / 60$ where it remained. Strangely enough, the pulse changes were greater in extent than in the controls.

After running up one flight of stairs, the patients failed to show either a pulse or a blood pressure rise as great as that in the normal controls.

Finally, it will be noted that Patient S usually felt faint immediately after rising from the lying position. On one occasion he was observed to lose consciousness and fall. He stated definitely that this experience was a faint and not an epileptic attack. Furthermore, he said that before the operation he had not had these symptoms.

TABLE III

Vascular reflexes after bilateral denervation of the carotid sinus. Patient $M$

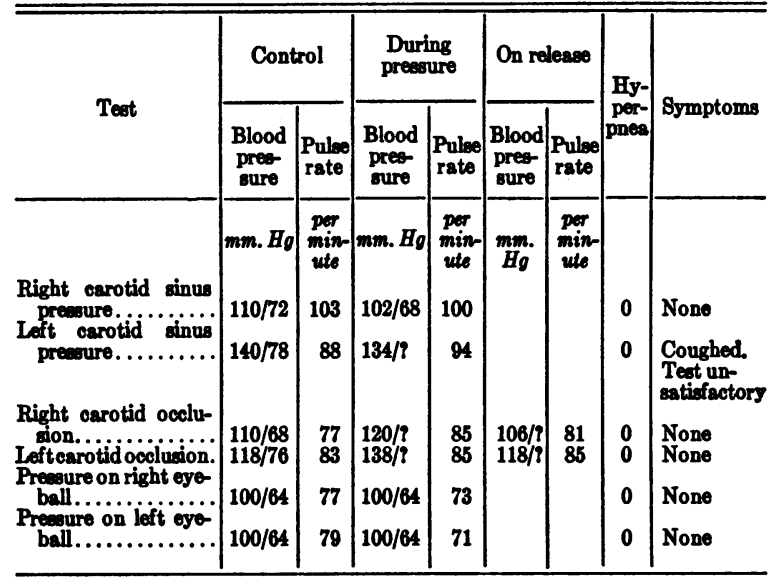

In Tables III and IV are shown the effect of carotid sinus pressure in each of the 2 patients. It will be noted that in Patient $M$ there was no definite response to any of the tests (Table III). The rise in blood pressure, with occlusion of the common carotid, might be so considered, but the lack of a depressor response on the release of pressure is in favor of some other explanation than a reflex from the carotid sinus.
TABLE IV

Vascular reflexes after bilateral denervation of the carotid sinus. Patient $S$

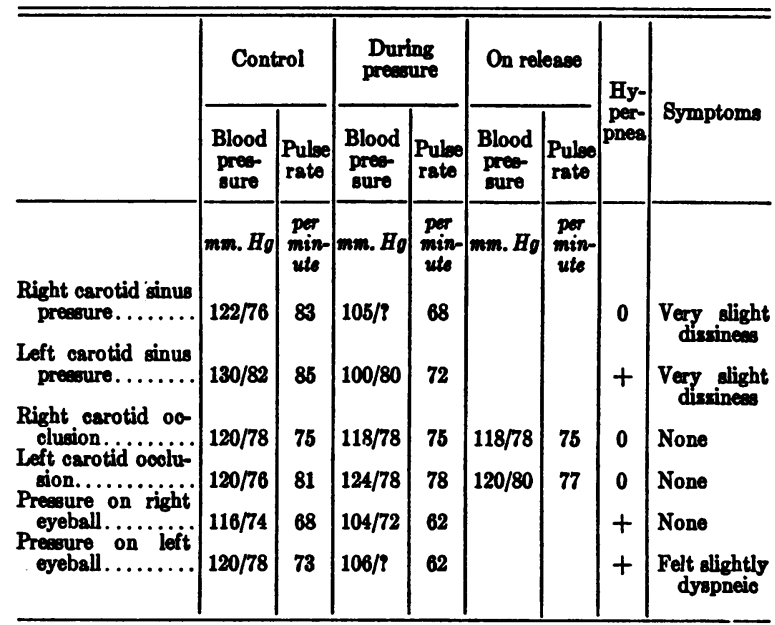

In Patient S (Table IV) there was a slight but definite response to direct stimulation of either carotid sinus. Occlusion of the common carotid failed, however, to induce any definite changes. Pressure on the eyeball in this patient caused a slight but definite fall in blood pressure and some slowing of the heart.

\section{DISCUSSION}

From the foregoing results it can be concluded that no permanent hypertension or tachycardia resulted from bilateral carotid sinus denervation. Furthermore, at the time of examination there was no evidence of increased sympathetic activity or increased lability of the blood pressure and pulse as might be demonstrated by exercise. However, on the other hand, there was a definite postural hypotension. Several questions concerning the validity of these conclusions immediately come to mind.

One first wonders whether the denervations were complete or whether regeneration of the nerves may not have occurred. This, of course, cannot be answered categorically. The actual operation performed was an extensive one that should result in a complete denervation. Temporary hypertension was observed following the second operation in both cases. This lasted for at least 12 days in Patient $M$ and for at least 4 days in Patient S. Because of the patients' discharge on these days, the duration of the hyper- 
tension is not known. Patient $\mathrm{M}$ also had a mild increase in pressure of $20 \mathrm{~mm}$. $\mathrm{Hg}$ after his first sinus denervation. This lasted for 7 days, at which time the second operation was performed. The hypertension in each case was of a considerable degree, reaching $152 / 100 \mathrm{~mm}$. $\mathrm{Hg}$ in Patient $\mathrm{S}$ and $146 / 100$ in Patient M. The production of hypertension lasting a number of days is evidence that most if not all of the carotid sinus fibers were sectioned. Further evidence that the sinuses were completely denervated is offered by the results of carotid sinus stimulation. Both direct mechanical stimulation of the sinuses and indirect stimulation by occluding the common carotid arteries gave no definite evidence of any physiological activity. It is true that in Patient $\mathrm{S}$ there was a mild response to direct pressure on both sides. This type of response has, however, been noted before in the absence of physiological activity (8). The explanation is not clear. Possibly the nerve stumps are sensitive (2). The presence of reflex changes from pressure on the eyeball simply demonstrates that other vasovagal reflexes are sensitive in $\mathrm{Pa}$ tient $S$. The next question that arises is that of the influence of the cervicodorsal sympathectomies. The 5 patients studied by Roth (11) and included as controls in Table II show that this operation does not effect the reaction to change in posture. On theoretical grounds, there should not be any effect on blood pressure reflexes. Furthermore, it is known that sympathetic accelerator fibers reach the heart through ganglia much lower than the second dorsal (12) which was the lowest one resected in our patients. In fairness, it must be said that the depressed acceleration of the pulse in the exercise test may have been owing, at least in part, to the section of the chief sympathetic nerve supply to the heart.

The absence of proper preoperative controls throws doubt only on the finding of postural hypotension. However, it seems unlikely that both patients would have shown this same phenomenon preoperatively and especially to such a marked degree. The absence of postural symptoms in $\mathrm{Pa}$ tient $\mathrm{S}$ before the operation is good evidence that they were the result of the denervation.

The significance of the more direct tests of the carotid sinuses is, of course, questionable because of lack of adequate preoperative control studies. The negative results, however, are consistent with complete denervation and absence of nervous regeneration.

The fact that bilateral denervation of the carotid sinus in man fails to produce a permanent elevation or an increased lability of the blood pressure or pulse shows that the aortic depressor mechanism is able to assume these functions of the carotid sinus in a reasonably satisfactory manner. Possibly also, as Breucker (13) has suggested, the type of specialized nerve endings found in the carotid sinus are more extensively distributed than generally thought. The postural hypotension can be explained on the basis of a relatively lower sensitivity of the aortic depressor mechanism than of that of the carotid sinus. Koch (14) has adduced experimental evidence in animals in favor of this assumption.

Whether or not certain cases of idiopathic postural hypotension are due to a mechanism similar to that of our two cases cannot be stated. Certainly, direct stimulation of the carotid sinus in such cases frequently reveals an absence of sensitivity $(15,16)$. It may well be that for various reasons the physiological sensitivity is diminished in certain individuals.

In conclusion, it should be emphasized that until further cases have been studied, the operation of bilateral carotid sinus denervation should not be undertaken lightly. It may be followed by unfavorable and even serious after-effects. It should not be performed unless the symptoms and condition of the patient justify the risk.

\section{CONCLUSIONS}

1. Two cases have been reported where a bilateral carotid sinus denervation and a bilateral cervicodorsal sympathectomy were performed. The vascular reflexes of these patients were studied 17 and $81 / 2$ months after the operations respectively.

2. There was no elevation of the blood pressure or pulse rate at this time as a result of the operation.

3. There was no increased lability of the blood pressure and the pulse as shown by an exercise tolerance test.

4. A marked postural hypotension was found in both patients.

5. Evidence that the foregoing findings were significant is presented. 
6. The possibility that a similar mechanism, namely loss of sensitivity of the carotid sinuses to normal physiological stimuli, may account for the findings in certain cases of idiopathic postural hypotension is pointed out.

\section{BIBLIOGRAPHY}

1. Hering, H. E., Die Karotissinusreflexe auf Herz und Gefässe. Theodor Steinkopff, Dresden and Leipzig, 1927.

2. Heymans, C., Bouckaert, J. J., and Regniers, P., Le Sinus Carotidien. G. Doin and Cie, Paris, 1933.

3. Heymans, C., and Bouckaert, J. J., Enervation des zones Vasosensibles Cardio-aortiques et Sino-carotidiennes. Technique. Influence sur les Reflexes Conditionels. Compt. rend. Soc. de biol., 1933, 112, 711.

4. Koch, E., and Mies, H., Utber die Physiologischen Wirkungen der Dauerausschaltung der Blütdruckzügler. Ztschr. f. Kreislaufforsch., 1927, 19, 589.

5. Wright, S., Studies of reflex activity in involuntary nervous system. J. Physiol., 1930, 69, 331.

6. Leriche, R., Fontaine, R., and Froehlich, F., L'Enervation Sinucarotidienne. Press. méd., 1935, 43, 1217.

7. Green, M. F., De Groat, A. F., and McDonald, C. H., Observations on denervation of the carotid sinuses and section of the depressor nerves as a method of producing arterial hypertension. Am. J. Physiol., 1935, 110, 513.

8. Ferris, E. B., Jr., Capps, R. B., and Weiss, S., Carotid sinus syncope and its bearing on the mechanism of the unconscious state and convulsions. Medicine, 1935, 14, 377.

9. Lauwers, M. E., Extirpation du Corpuscle Carotidien dans l'Epilepsy. J. de chir., 1931, 37, 686.

10. Danielopolu, D., Sur la Pathogénie de l'Epilepsie et sur son Traitement Chirurgical. Press. méd., 1933, 41, 170.

11. Roth, G. M., The postural effects on blood pressure following interruption of the vasomotor nerves of man. Am. Heart J., 1937, 14, 87.

12. White, J. G., The Autonomic Nervous System. MacMillan Co., New York, 1935.

13. Breucker, W., Das Pressorezeptorische Nervensystem und seine Prelitische Bedeutung in der Chirurgie. Beitr. z. klin. Chir., 1933, 158, 309.

14. K.xch, E., Die Reflektorische Selbststeurung des Kreislaufes. Theodor Steinkopff, Dresden and Leipzig, 1931.

15. Lian, C., Stoicesco, S., and Vidrasco, C., De l'Etat du Système Nerveux Végétatif dans l'Hypotension et l'Hypertension Artérielles Permanentes. Press. méd., 1929, 37, 1309.

16. Ellis, L. B., and Haynes, F. W., Postural hypotension with particular reference to its occurrence in disease of the central nervous system. Arch. Int. Med., 1936, 58, 773. 